\title{
IMPACT OF E-MARKETING ON CONSUMER BEHAVIOR
}

\author{
Lidija Pulevska Ivanovska ${ }^{1}$ \\ Ss. Cyril and Methodius University, Faculty of Economics, Skopje, \\ Republic of Macedonia \\ Elena Karadakoska \\ Ohrid, Republic of Macedonia
}

\begin{abstract}
Electronic marketing or e-marketing means using digital technologies that in a complementary relationship with traditional marketing methods will create interest among consumers that will lead to a decision of buying the product or service offered. Emarketing has to be creative, constantly changing and interesting in order to keep the attention of the consumers, who nowadays have large amount of information at their disposal. In order to identify the level of awareness of e-marketing among the population of the Republic of Macedonia and the impact of e-marketing on consumer behavior, a research was conducted on a sample of 137 respondents.
\end{abstract}

Key words: electronic marketing, consumer, Internet age, Republic of Macedonia.

\section{INTRODUCTION}

The Internet as a new communication medium that creates new kind of global virtual market, without spatial and temporal boundaries, has completely changed the media picture of the world. This fast growing technology with its simplicity of use and availability on a broad customer base provides lots of benefits to the companies. The interactivity as a major feature of the Internet leads to a new dimension of relationship between all market participants, which refer to interconnection between clients, and connection of the clients with the companies, that creates a strong concern between entities.

The Internet has significantly contributed for the change of the mass marketing form (traditional marketing) that focuses on gaining attention to an "average customer", to individualized, targeted marketing that recognizes and accepts the uniqueness of each customer and through direct interaction tries to get their attention. The electronic marketing covers all online activities that allow companies to meet the desires and needs of their customers in a quick and very effective manner. The basic idea of the electronic marketing is creating better connection between the companies and the customers, and winning the customers before competition. The electronic marketing is based on immediacy,

\footnotetext{
${ }^{1}$ lidijap@eccf.ukim.edu.mk
}

Vol. 17, број 4/2015, стр. 67-81 
personalization and relevance, which connect the companies with the target group of customers who in today's e-society have the opportunity to choose what will deserve their attention.

The modern consumer, who is continuously educated and knows how to use the power of the online communication, has different requirements and expectations from the companies. The availability, accuracy, experiences of previous users, speed of delivery, information about discounts and special offers are only part of the information that helps consumers to select a specific product. And since in this online era customers with a single click can "go" from company to company and buy a product, it is recommended the marketing departments of companies to be original, creative and undergoing constant change, in order to keep the attention of modern consumers (e-consumer).

Electronic marketing provides more modern marketing methods to the companies, which include: search engine marketing, which includes search engine optimization and pay per click advertising; e-mail marketing; affiliate marketing; banner ads that appear on web sites; video ads that are available online, or video marketing; social media marketing, in which the most evident is Facebook marketing, due to its widest consumer coverage, and also Twitter marketing; modern viral marketing and mobile marketing. All these methods offer a series of advantages to companies, if they are successfully applied in the brand creation, which can significantly influence the improvement of company's work.

\section{MODERN COMMUNICATION WITH THE MODERN CONSUMER}

"Consumer behavior is one of the most subtle issues of the theoretical concepts of marketing. The main reason for this is the individuality of a person in the process of decision making, and the inability to perceive the internal motives and psychological elements that in a certain way affect the nature of the decision. "(Ristevska-Jovanovska and Jakovski, 2004, p. 3)

Belch and Belch (2003), define consumer behavior as a process and activities that are typical for consumers in their product selection process, procurement, evaluation, use or stop using the products or services according to their needs and desires.

The main objective of the marketing campaigns of modern companies is to influence the decision of purchasing a product or service. Moving towards their main goal, companies are finding that the buying decision is only part of a bigger process. The success of companies and the realization of their main goal largely depend on how well companies 
understand the consumer behavior (Belch and Belch, 2003). The understanding of the consumer behavior, in fact, is an important competitive advantage for companies. Marketing strategies and tactics are built on a series of explicit and implicit assumptions about consumer behavior. The decisions which are based on explicit assumptions and research will be more successful than those decisions that are based on intuition (Hawkins and Mothersbaugh, 2010).

A key factor that directly affect consumer behavior, and also the success of electronic marketing, is the degree of involvement of consumers in the methods of electronic marketing.Different degrees of involvement bring different groups of consumers for the companies, with different behaviors (Wu, 2002). According to Brinker (2009), and as noted by Smith and Zook (2011), modern companies should include five new skills in modern marketing communications sector for successful communication with the modern consumer. Those are:

* Analytical skills. Skills related to research on the flow of feedback from social media, web analysis, transaction histories and profiles of consumer behavior.

* Effective project management. The tactical campaigns are detailed and fragmented, and directed to tens, hundreds or thousands of different contexts, which requires greater skills in project management.

* Experimental curiosity. Modern markets require constant improvement and increased return on investment. Because of that, the marketing communications sector must constantly make tests, analyses and researches.

* System thinking. Marketing is a set of processes. This implies the need of connecting the parts or the results of the various analyses of processes.

* Connecting different software. Modern marketing offers applications, pictures, videos, games. Integration of these different methods is needed for success.

The ability to adapt is the biggest advantage of any modern and successful enterprise. Consumer orientation is the main precondition for successful adjustment and performance in the modern world. Successful adaptation is not just implementing new technologies and methods of communication, but leading a company to create a marketing strategy that will separate it from the competition and will guarantee success (Zivkovic, 2011). 


\section{RESEARCH METHODOLOGY}

The focus of this research is on the perception of consumers regarding application of the methods of electronic marketing in the company's operation. The research is specifically directed to the consumers in the Republic of Macedonia, by analyzing their knowledge, their attitudes toward electronic marketing and the impact of e-marketing methods on their behavior.

A sample of 137 respondents from Republic of Macedonia is surveyed. The survey was conducted online in June 2015. The questionnaire was created online on the website kwiksurveys.com, and through the same page is administered. The questionnaire consists of 15 questions with answers offered.

\section{ANALYSIS OF THE SURVEY RESULTS}

Of the total 137 surveyed respondents in terms of age category, $59.12 \%$, or 81 person of the respondents are in the age group from 26 to 35 years, $35.04 \%$ are aged 15 to 25 years (48 persons), $438 \%$ are aged 36 to 45 years (6 persons) and two respondents, or $1.46 \%$ are over the age of 45 years.

According to the educational level, 89 of the surveyed respondents, or $64.96 \%$, have bachelor degree, 36 respondents or $26.28 \%$ have a master's degree, while 12 of the respondents or $8.76 \%$ have secondary education.

On the question: What kind of marketing attracts the most of your attention?, $63.5 \%$ of the respondents surveyed (87 respondents) said that the most attractive is the electronic marketing, 26.28\% (36 respondents) choose television marketing, 9.49\% (13 respondents) informative billboards, and only one respondent replied that the ads on radio and newspaper ads attract his attention.

The results indicate a positive trend of noticing the electronic or internet marketing among the surveyed respondents. Electronic marketing has attracted a large amount of interest at $63.5 \%$ of the respondents, which is an expected result because of the modern lifestyle and the increased time that people spend on line. This fact indicates on the great potential and power of the electronic marketing to generate new and retain the permanent clients of a modern company. According to the results, if a company wants to leave a good impression and attract the attention of its target group, it should focus on introduction of electronic marketing methods in their marketing strategy and tactics. 
On the other hand, it is obvious that marketing through radio and newspaper ads, no longer attract attention from consumers. Even the trend of listening to the radio and reading a newspaper is in a significant fall due to the appearance of the Internet and the limitless possibilities that it offers to people.

* According to the age category, amongst 87 respondents who answered that electronic marketing attracts the most of their attention (63.5\% of the total respondents), 47 belong to the age group of 26 to 35 years and 36 respondents belong to the age group of 15 to 25 years.

* Amongst 36 respondents who answered that television marketing attracts the most of their attention $(26.28 \%$ of the total number), according to the age category 26 respondents belong to the age group of 26 to 35 years and 7 respondents belong to the age group of 15 to 25 years.

Figure 1.: Number of respondents of different age groups whose attention is the most focused on television and electronic marketing

$\square$ 26-35 years $\square 15-25$ years $\square$ Other age groups

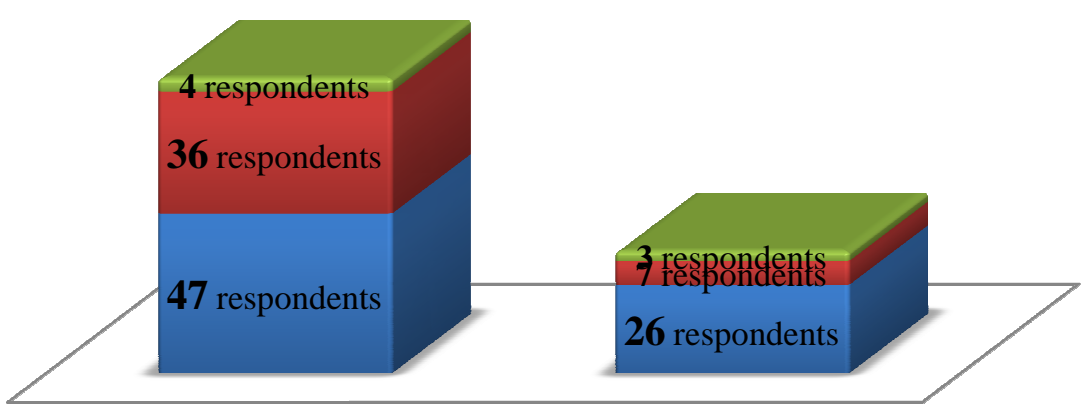

Electronic marketing Television marketing

Source: Individual research

According to Figure1, the attention of $58 \%$ of the respondents in the age group of 26 to 35 years (47 respondents), is attracted by the electronic marketing, and $32 \%$, or 26 respondents are most attracted by television marketing activities. These data suggest that electronic marketing is definitely the most significant type of marketing widely covered in both age groups and has attracted large amount of attention, but also television marketing ranks well on the range of types of marketing activities, taking the safe second place, without competition. 
On the question how respondents acquire information about a specific product or service, 111 of the respondents, or $81.02 \%$ answered that they search data and information on the internet search engines (mostly on Google), 84 respondents or $61.31 \%$ searched Information on the website of the company, $39.42 \%$, or 54 people acquire information through social media. Other $30.66 \%$, or 42 people ask their acquaintances, and only 5 respondents or $3.65 \%$ think that through the internet one cannot obtain a clear picture of the characteristics of products or services.

Figure 2.: Methods of acquiring information

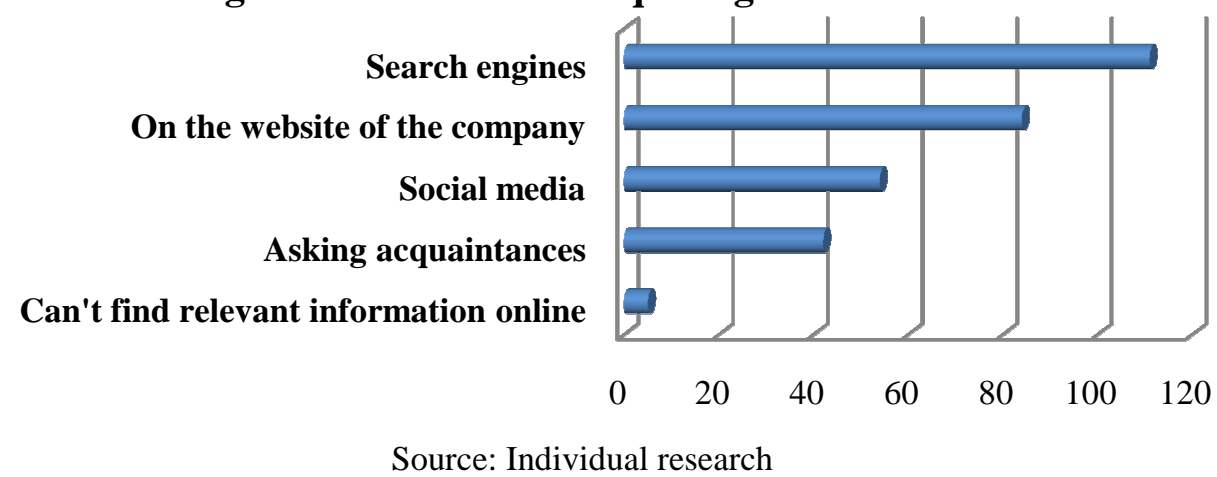

Because of the many ways that are available to modern consumers for information acquisition, in answering this question respondents could select up to three responses, because we all strive for maximum use of all opportunities offered.

* According to the data, the most consumers acquire information through search engines, a fact that should be pointed out to companies, and speak how important search engine marketing is with its methods - search engine optimization and pay per click advertising.

* A second way of acquiring information according to the questionnaire, is reviewing the website of the company. It is clear that nowadays customers expect company's websites to contain updated and detailed information for the company work and its products and services.

* The third way of acquiring information is the social media (mostly Facebook). This data speaks of the expectations that modern consumers have from the activities of the companies on the fan pages and groups on social media.

Regarding the usage of social media, undoubtedly unrivaled first place is reserved for Facebook. According to the research, 79 of the respondents are active on Facebook less than three hours a day, and 57 
people are active on Facebook for more than three hours a day. The use of Twitter among respondents is small, and only one of the respondents does not use social media.

Figure 3.: Activity on social media

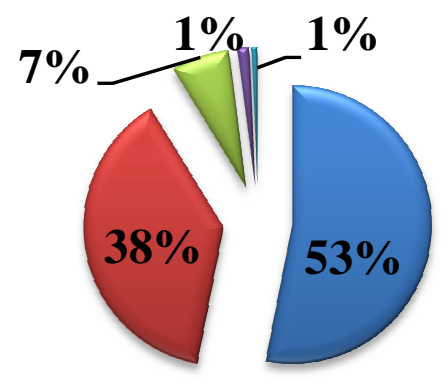

$\square$ Facebook less than 3 hours a day

$\square$ Facebook more than 3 hours a

day

$凶$ Twitter less than 3 hours a day

$\square$ Twitter more than 3 hours a day

$\square$ I don't use social media

Source: Individual research

On the question does the ads on social media attract the attention of the respondents, $76 \%$ of the respondents answered that they notice the ads, and click on them if they achieve their attention. Only 7 persons $(5.19 \%)$ always click on ads on social media, and 26 people or $19.26 \%$ said that ads on social media do not attract their attention.

The data from this survey question bring companies to the term creating a moment of interest to consumers. In the modern world, consumers spend more time online and as noted above, their daily social media activity is high. Moreover, they are constantly influenced by many different ads that the social media marketing provides to companies, and it is noticeable that modern companies use this method on a higher level.

The moment of interest is very important and crucial point which is in the focus of all companies that use social media marketing, because as you can notice from the data of this questionnaire, $76 \%$ of respondents click on the ads only if they are interested, and that is quite understandable, since any person direct significant attention to the things that are interesting.

To attract the attention of consumers, the marketing departments of companies should express their creativity and innovation. These are much appreciated characteristics with power to create a point of interest among potential customers and differentiate the company and its products / services among lots of ads and information that the modern consumer gets online. 
The attitude of the respondents toward mobile marketing or advertisements that are displayed when using internet on the smart phones, according to the data provided by the questionnaire is ignorant.

Figure 4.: Attitude of surveyed respondents toward the ads on smart phone

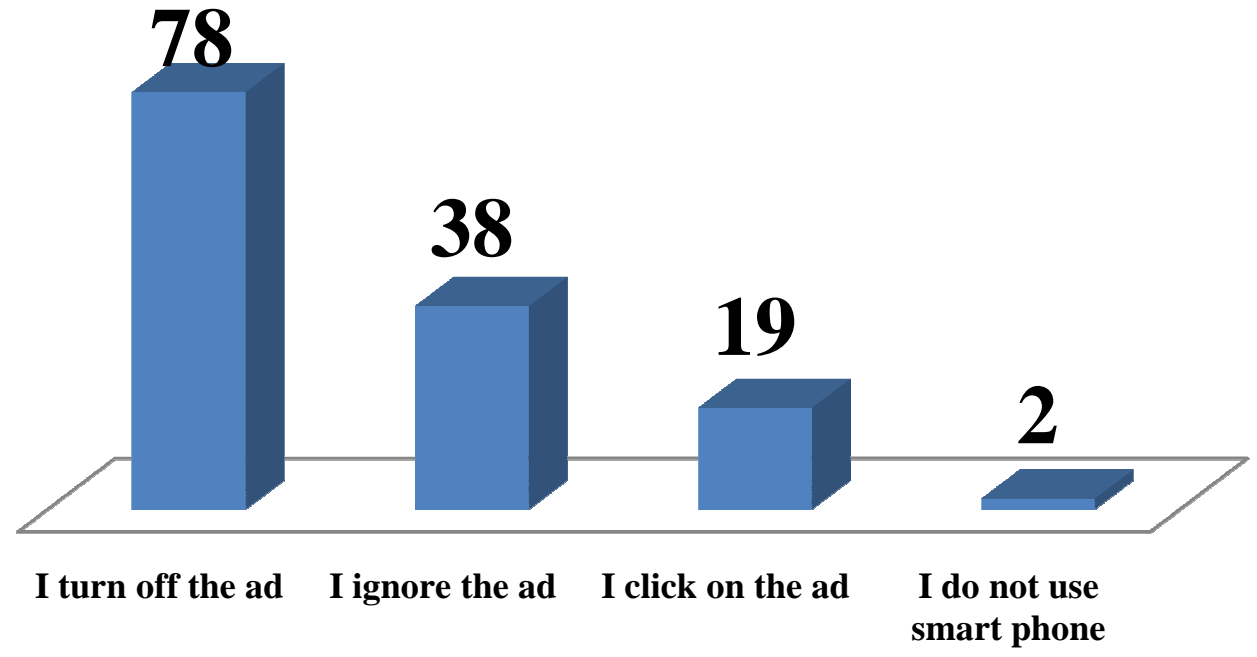

Source: Individual research

According to the survey results as shown in Figure4, 57.35\%, or 78 respondents, who were exposed to ads while using the internet on their smart phones, turn off the ad, and 38 of them (27\%) ignore mobile advertising. The act of turning off the ad is associated with aversion to this kind of marketing, while ignoring the ads indicates that they do not produce any interest among the surveyed respondents. Only $13.97 \%$ of the respondents said that they click on the ad, and that such ads cause interest among them, and two of the respondents said they do not own and use a smart phone.

From the data above, a conclusion can be made that the interest in this type of marketing is still very low among consumers in the Republic of Macedonia. The number of respondents who turn off the ads without ever seeing their content is high. Companies that use mobile marketing should carefully use planned strategy and tactics that will be properly directed to the target group, sent in the real time to be noticed.

Regarding the banners (advertisements) on web sites, 70 of the respondents answered that they open those banner ads that will create interest, which represents $51 \%$ of the total number of respondents. In contrast, $23 \%$, or 32 respondents answered that they are annoyed from 
banners while browsing certain website. 22 respondents ignore banners, and 13 turn them off.

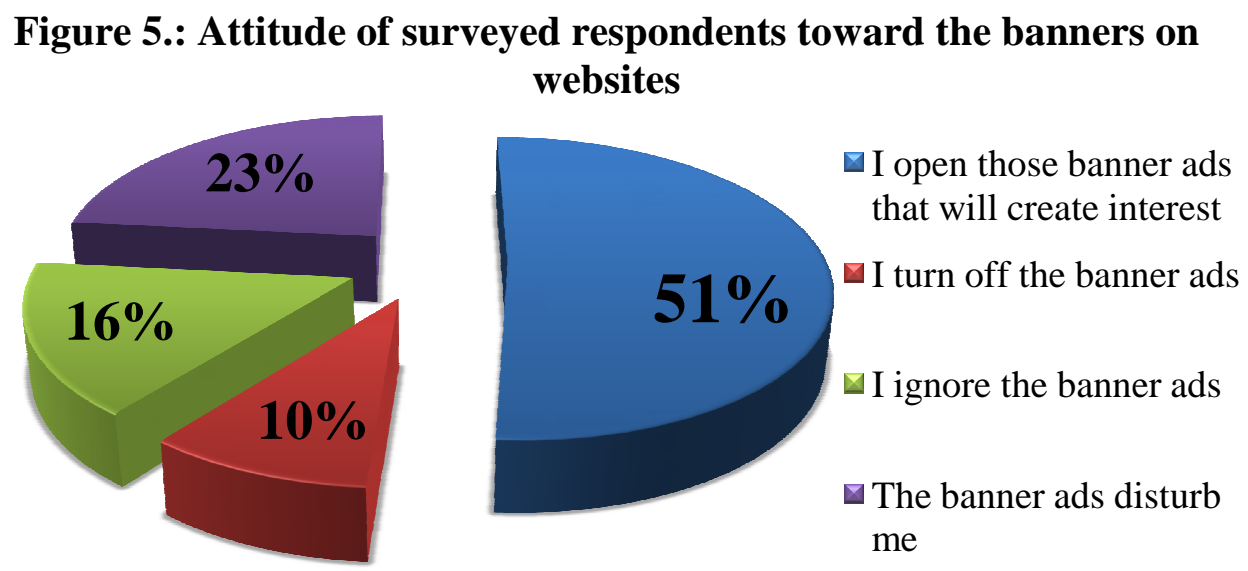

Source: Individual research

Banner ads should be customized to attract the attention of consumers. To achieve success, special focus should be put on the integration of modern technology into the interactivity of the banners and combining audio and video effects, creativity and inventiveness of the marketing teams of the companies. Also companies need to be careful on the size, shape, color, position and movement of the banners throughout the site, if there is such possibility.

On the question about the reaction of respondents to the email they receive as promotional or informational material, $69.12 \%$ of the respondents, or 94 respondents said that they read the e-mail only if they are intrigued by the title of the message. Key aspect of creating interest, as stated above, is the title of the message, which will indicate to the recipients that the message content will be useful and that they should open it and read it. Only 7 of the respondents (5\%) said that they always read the messages, and $35(26 \%)$ always delete e-mail promotional and informational materials. Therefore, it is obvious how difficult is task of marketing departments in companies that use e-mail marketing as a method of the electronic marketing in their operations, to create interest among consumers only through a few words in the title of the message.

The attitude of the surveyed respondents to video marketing or online video ads, according to data obtained from the completed questionnaire is very characteristic. When answering this question, respondents had the opportunity to choose one, two or three answers, in order to be created connection between the ratings of the video ads with their share on social media on one hand and on the other hand examining

Vol. 17, број 4/2015, cmp. 67-81 
how many people find video marketing more attractive than any other type of marketing.

* $46 \%$ of the respondents, or 62 people said that they watch online videos and in their opinion the video ads are better way of advertising in modern society. Of these $46 \%$ of the respondents, 20 belong to the age group of 15 to 25 years, 39 belong to the group of 26 to 35 years and 3 persons belong in the age group of 36 to 45 years.

* The percentage of respondents who do not watch online video ads is also $46 \%$, correspondingly in this group belong 63 people. Of these $46 \%, 24$ respondents belong to the age group of 15 to 25 years, 34 respondents belong to the age group of 26 to 35 years, 3 people are in the age group of 36 to 45 years and two people above 46 years who completed the questionnaire said that they watch online videos.

The ratings of the video ads, according to the number of respondents from the particular age groups find divided opinions. Because of the fact that this type of electronic marketing is still new and not often practiced by companies in the region, it is not yet fully accepted by internet users.

* Only 10 of the respondents said that they watch video ads and share them on social media, but this number is significantly small. In contrast to the global trend of spreading online videos, as a feature of modern viral marketing, according to the results of the questionnaire in the Republic of Macedonia, this trend is not yet fully accepted.

* Also, according to the general picture of the answers to this question and the fact that video ads attract the attention of only 12 respondents more than any other type of marketing, it can be concluded that this type of marketing does not have the attention as it deserves.

According to the questionnaire data, regarding the usage of electronic marketing in the work of companies in Republic of Macedonia, the majority of respondents (69\%) think that the methods of electronic marketing are used by the large and financially powerful companies. Significantly smaller number of respondents $(27 \%)$, think that the small and medium enterprises use methods of electronic marketing in their work, while only $4 \%$ think that companies in the Republic of Macedonia do not use methods of electronic marketing in their marketing strategy.

The fact that the largest percentage of respondents, believe that the methods of electronic marketing are mostly used by the large and 
financially powerful companies indicates that they perceive the electronic marketing as an expensive investment that not everyone can afford. This is an outcome from their experience in the daily usage of the Internet, and suggests that the respondents notice the internet marketing activities of the large and financially powerful companies, because of their intensity and broad representation.

Regarding the question what methods of electronic marketing are most noticeable, on the first place according to the surveyed respondents is the social media marketing, on the second place are the banners on websites and in the third place is the search engine marketing.

Because of the fact that the respondents are on daily base under impact of all methods of electronic marketing, the purpose of this question was actually to find out which methods are most noticeable between the internet users and which methods leave impression on them.

Figure 6.: Level of noticing the methods of electronic marketing

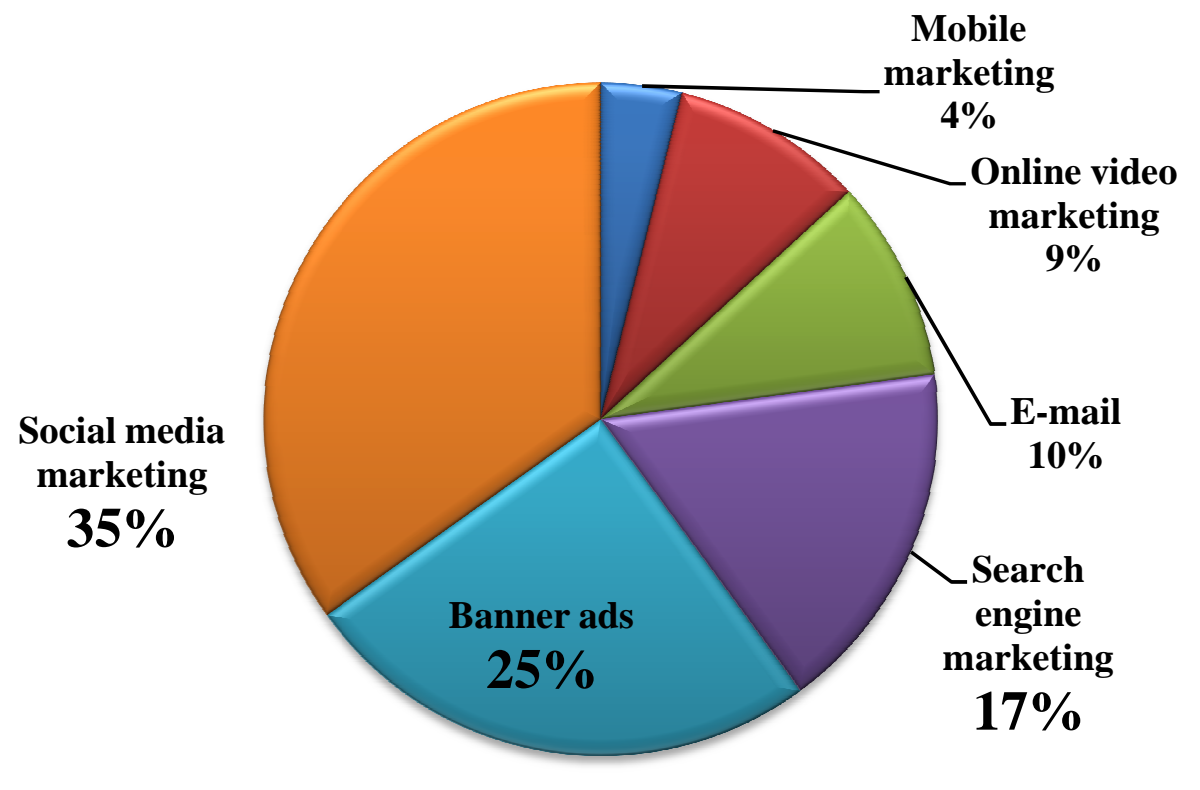

Source: Individual research

Appropriate with the responses to the previous questions, $35 \%$ of the respondents noted the activities of companies on social media, $25 \%$ notice banners on websites, and $17 \%$ of the respondents, notice search engine marketing. Email marketing, online video marketing and mobile marketing have significantly lower percentage of attraction among internet users. These data indicate on which methods companies should focus, in order to be noticed by consumers. 
According to the online buying, 53 of the surveyed respondents believe that it is safe to buy online, and only 14 of them think that it is not safe to buy online. This indicates a growing trend of creating trust in online shopping among consumers. The fear of stealing personal information and money, which significantly influences the creation doubt in electronic commerce and electronic business in general, is already omitted, and consumers use the advantages provided by the modern society.

Expectations that modern consumers have from the modern companies, are the best reflection of their needs. A successful modern company should focus on achieving the expectations of its regular and potential clients to achieve success in every field.

\section{Figure 7.: Expectations from modern companies}

To have updated website with relevant information about the products/services

To be active on social media

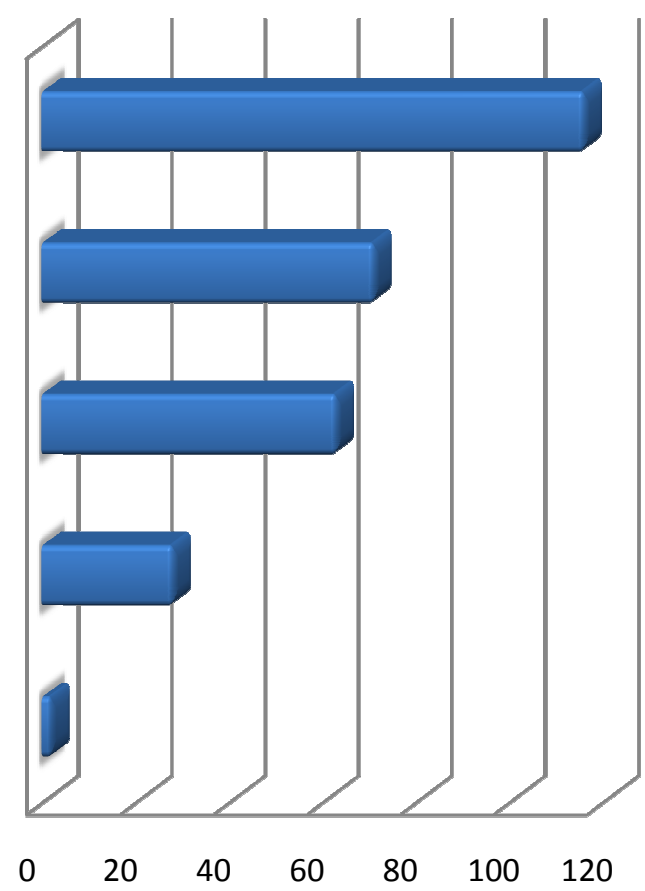

Source: Individual research

According to the data from the questionnaire, the highest expectations are based on the website of the company that should be rich with relevant and updated information about the company and its products or services. The activity on social media and sharing the offers of the company on the fan page or group administered by the company, is also 
of great importance to customers because social media (especially Facebook) become relevant information medium in the modern society. According to the increased trust of consumers and companies in electronic transactions, electronic commerce and electronic business in general, the expectations for launching an electronic store, where customers will be able to order the company's products online and also pay online by credit card, are increasing, which will save part of their free time.

In terms of evaluation of the company activities related to the methods of electronic marketing, having electronic store (according to the opinion of 64 of the respondents) and the activity of companies on social media, (according to the opinion of 63 of the respondents)are considered as very important activities.

Figure 8.: Evaluation of the activities of companies related to the methods of electronic marketing

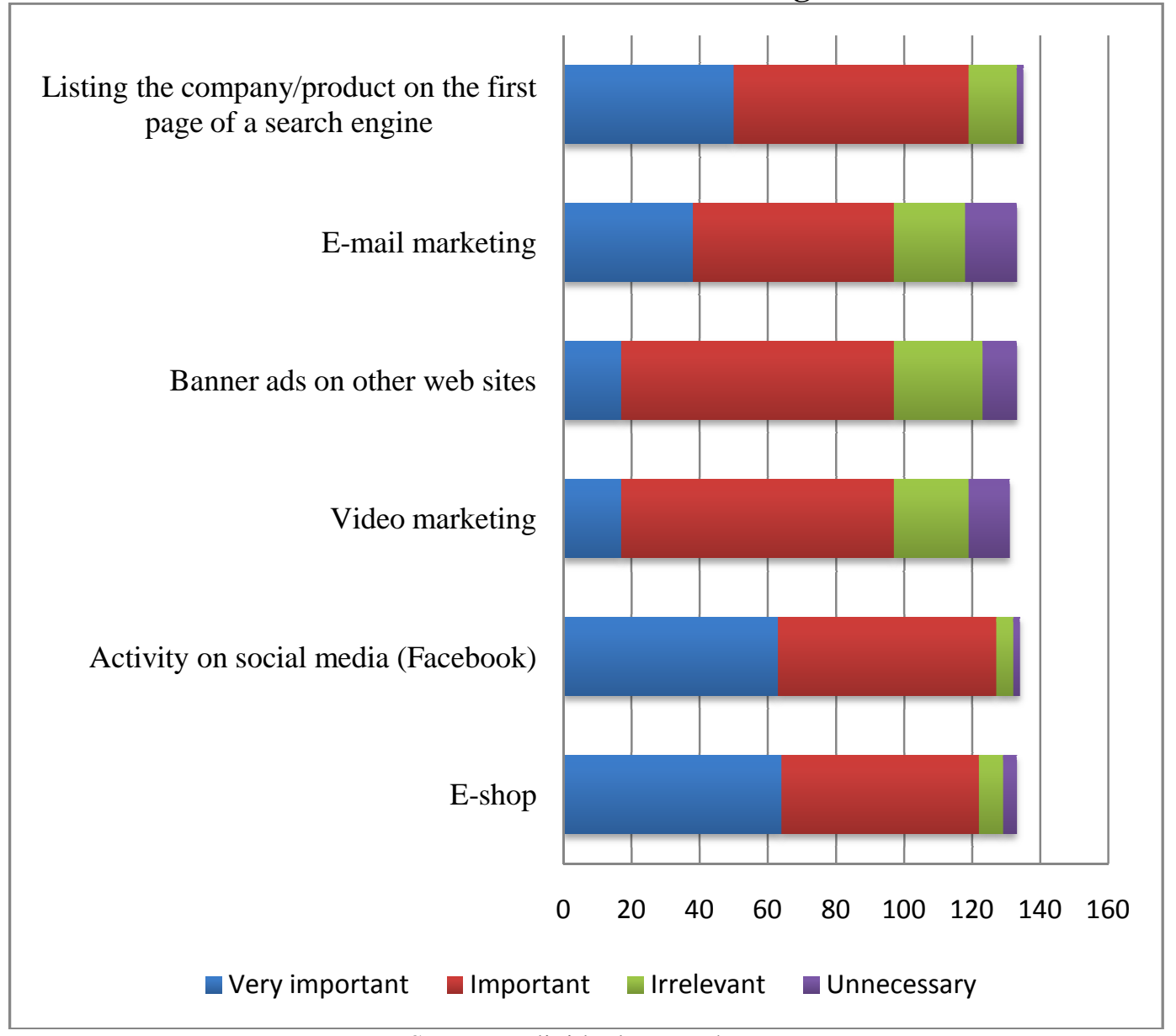

Source: Individual research 
The majority of the surveyed respondents ( 80 people), consider that the two important activities for businesses are the online video ads and setting banners on other websites. Listing of the product/company on the first page of a search engine is an important activity according to 69 respondents and the activities on social media as an important activity is considered by 64 respondents. E-mail is an important activity according to 59, and having an electronic store, according to 58 respondents. All methods of electronic marketing, presented to respondents as activities that are implemented in the modern companies, by the majority of the respondents are considered as important activities for development and survival of the company in the modern society.

\section{CONCLUSION}

Companies in the Republic of Macedonia enter the internet era step by step, and begin to fit into the digital world. In the Republic of Macedonia, the electronic marketing is still a new trend for companies and has not still achieved satisfactory level of usage which could bring more positive results. The tendency of companies to introduce methods of electronic marketing in their marketing mix and performance is remarkable, and it is obvious the desire of the companies to fit into the digital world and take advantage of the benefits offered by electronic way of working.

The modern Macedonian consumer has already built his expectations from the modern companies. Consumers from the Republic of Macedonia are looking forward the implementation of the methods of electronic marketing in the marketing mix of the companies, and intensive usage of successful combination of electronic marketing and traditional marketing, according to the behavior of the target groups of the companies.

Many companies often use the methods of electronic marketing in inappropriate manner, for example by placing the same advertisements through more than one media. This inappropriate usage of the methods of electronic marketing brings awareness about the insufficient knowledge about the internet marketing of companies on the one hand, and the need for organizing conferences and seminars with educational character on the other hand, which will guide companies in the Republic of Macedonia on the way to success and to the proper usage of the benefits that are provided by the digital age.

The impact of electronic marketing on consumer behavior is undoubtedly very important. Due to this fact, companies need to seriously approach the introduction of electronic marketing in their marketing 
strategy and usage of optimal combination of its methods to achieve greater brand awareness, create interest among consumers for their products and services and to fit into the modern digital society.

\section{LITERATURE}

1. Belch, G.E. and Belch, M.A. (2003), Advertising and Promotion. An integrated Marketing Communications Perspective, $6^{\text {th }}$ edition, McGraw-Hill, New York, pp.105, pp.127-129

2. Ellis-Chadwick, F. and Doherty, N.F. (2012), "Web advertising: the role of email marketing", Journal of Business Research, Vol.65, No.6, pp. 843-848.

3. Harden, L. and Herman, B. (2009), Digital engagement, AMACOM, New York.

4. Hawkins, D.I. and Mothersbaugh, D.L. (2010), Consumer behavior. Building marketing strategy, $11^{\text {th }}$ edition, McGraw-Hill Irwin, New York, p.9, p.27

5. Kiang, M.Y., Chi, R.T. (2001), "A framework for analyzing the potential benefits of internet marketing", Journal of Electronic Commerce Research, Vol.2, No.4, pp.158-160.

6. Ristevska-Jovanovska, S. and Jakovski, B. (2004), Odnesuvanje na potrosuvacite, $2^{\text {nd }}$ edition, Faculty of Economics, Skopje, Republic of Macedonia, p.3

7. Simmons, G. (2008), "Marketing to postmodern consumers: introducing the internet chameleon", European Journal of Marketing, Vol.42, No.3/4, pp.299-306.

8. Smith, P.R. and Zook, Z. (2011), Marketing Communications. Integrating offline and online with social media. , $5^{\text {th }}$ edition, Kogan Page Limited, London, pp.133-134

9. Wu, S. (2002), "Internet Marketing Involvement and Consumer Behavior", Asia Pacific Journal of Marketing and Logistics, Vol.14, No.4, p.37

10. Zivkovic, R. (2011), Ponasanje potrosaca, $1^{\mathrm{vo}}$ izdanje, Univerzitet Singidunum, Beograd, str.3, str.8, str.113-123 